\title{
PROPOSING DIGITAL MODELS FOR THE DISCUSSION OF CONTESTED CONSERVATION PRACTICE: CASE STUDIES FROM TAMIL NADU, INDIA
}

\author{
O.E.C. Prizeman ${ }^{1 *}, \mathrm{C} \mathrm{Branfoot}^{2}, \mathrm{~K} \mathrm{Rao}^{3}$, A. Hardy ${ }^{1}$ \\ ${ }^{1}$ WSA, School of Architecture, Cardiff University, King Edward VII Avenue, Cardiff, UK - (prizemano, hardya) @ cardiff.ac.uk \\ ${ }^{2}$ School of Arts, SOAS University of London, Thornhaugh Street, London, WC1H 0XG UK - cb68@soas.ac.uk \\ ${ }^{3}$ SPA, School of Planning and Architecture, Vijayawada, India - kailashrao@spav.ac.in
}

Commission II, WG II/8

KEY WORDS: Contested Conservation, Digital Models, Temple Conservation, Photogrammetry, Laser Scanning, Tamil Nadu, India

\begin{abstract}
:
This paper explores the potential for digital surveys to mediate as tools in a complex arena. As increased wealth and continuous religious practice have supported the energetic maintenance and renovation of temple buildings in Tamil Nadu justified by reference to ancient texts, UNESCO commissioned a fact-finding mission regarding conservation practice there in 2016. As part of wider project to investigate the strands of inherited textual guidance in this sensitive area, digital documentation methods are being tested in terms of their capacity to provide a locus for discourse between divergent views at a time of rapid formulation of policy documents that seek to offer guidelines for the conservation of an estimated 38000 temple buildings in the state. This paper outlines some challenges and ambitions of creating digital platforms to serve such an endeavour through potential scenarios offered by two case studies. Specifically, it considers the merits of tools to read urban encroachment, to identify change over time and to explore a means to provide a hypothetical platform for discussion of potentially sensitive adjustments.
\end{abstract}

\section{INTRODUCTION}

1.1 The need to mediate between "bottom up" and "top down" conservation principles

Silverman in her historiography of the literature of contested cultural heritage (Silverman 2011), highlights Byrne as the first to question the UNESCO 1972 World Heritage Convention's assertion of Universal Value as representing an exclusive Western hegemony blind to subaltern contributions (Byrne 1991). The Burra Charter defined Cultural Significance as the "aesthetic, historic, scientific, social or spiritual value for past, present or future generations" (ICOMOS 2013). This precept represented a shift in emphasis (Worthing and Bond 2008) with respect to the values that determine the formulation of policies with respect to the management of cultural heritage.

In the context of the ICOMOS 2017 Delhi Declaration on Democracy and Heritage, the question of "who decides?" was placed at the forefront of global consciousness on heritage issues. With respect to negotiating authoritative recommendations, the problems are manifestly ethical and theoretical but also practical and grounded in terms of their attachment to physical and tangible heritage. In challenging the interaction between the continuity of traditional knowledge and the rights of the objects to which that is applied there is a risk of building yet a further layer of authority. For that reason, the aim of this paper is to focus on the creation of accessible knowledge through the medium of digital tools in order to enable greater scope for reflection.

The paper explores the potential for digital documentation tools to mediate complex issues of contested heritage in the context of temple renovations in Tamil Nadu, India. Sites were physically scanned using both Terrestrial Laser Scanning (TLS) and Structure From Motion (SFM) techniques. The models will be used for building both three-dimensional models as well as layered historical plans that can allow knowledge and legacies to be located spatially. In doing so, it should be possible to develop further the potential for Virtual Reality (VR) to contribute to heritage discourse both at a strategic and a practical level.

\subsection{The maintenance of temples of Tamil Nadu}

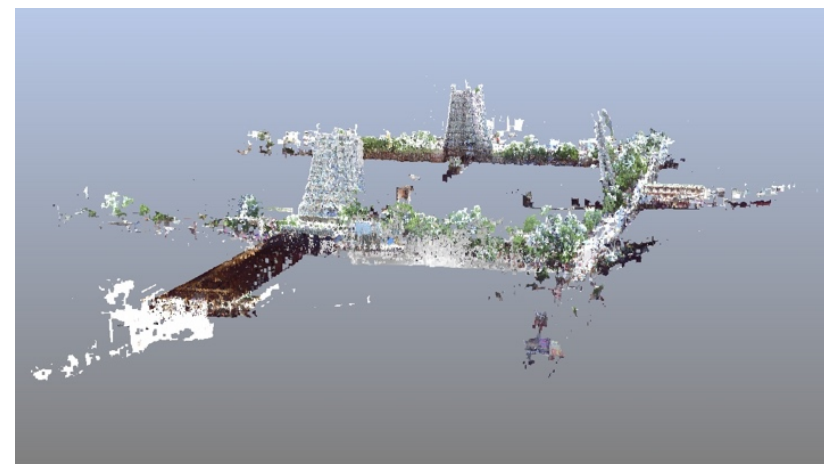

Figure 1. Pointcloud showing Pudu Mandapam (in the foreground) in relation to W, N and E Gopura of the Minakshi Sundareshvara temple, Madurai, Tamil Nadu, India

There are rising numbers of visitors to Madurai and other temple towns - some are foreign tourists, but the main growth in numbers is from domestic tourism and pilgrims. As living sacred sites, many of the largest and most important temple-towns in Tamil Nadu have been pilgrimage destinations for centuries. Numerous low-cost airlines and an ambitious road-building programme since 2010 together with an enhanced social media presence have enabled an increasing number of pilgrims to visit the most important temples, especially at important annual

* Corresponding author 
festivals when the numbers can overwhelm temples and their urban settings. This is one of the driving forces behind many temple management committees' decisions to renovate temples.

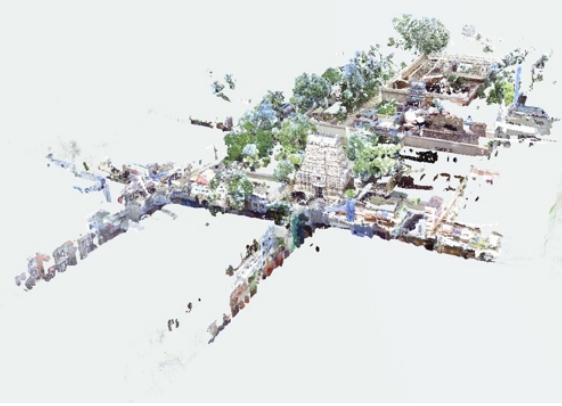

Figure 2. Pointcloud showing Nageshvara temple at Kumbakonam, Tamil Nadu, India

What does 'renovation' (Tamil tiruppani, Sanskrit jirnoddhara) mean? Periodic renovation is a routine part of the ongoing lives of south India's temples (Branfoot 2013). In recent years at some temples this has entailed merely touching up plasterwork and repainting the brightly-painted images of deities on temple towers and gateways before a lavish reconsecration (kumbabhishekham) of the temple. But at other temples, ancient shrines and gateways have been demolished and rebuilt, high enclosure walls raised or 'straightened' and new columned halls erected. At busier temples thronging with visitors, metal fences have been erected in the granite floors to control pilgrims' movement, or marble slabs cemented over thousand-year old inscriptions. Indiscriminate sand-blasting of medieval stonework has resulted in the disappearance of traces of rare seventeentheighteenth century mural paintings or damaged relief sculptures. It is the increasing expenditure and lavish scale to which some temples have been transformed that aroused the concern - or indeed utter dismay - of some communities of devotees and indeed government archaeologists. Several court cases brought against the Hindu Religious and Charitable Endowments (HR\&CE) government department responsible for the upkeep of the huge number of Tamil Nadu's active, 'living' temples resulted in the High Court in Chennai instructing UNESCO in 2016 to commission a fact-finding mission. How could Tamil Nadu's religious practices, piety and agamic prescriptions revealed by God accommodate the 'heritage-value' of ancient monuments? How can popular religion transform world heritage discourse? Who do these temples belong to?

\section{THE ISSUE OF TEMPLE "RENOVATIONS"}

There are significant historical legacies to the practices of the replacement and re-instatement of Tamil temple structures over the past millennium that have often been overlooked in contemporary heritage discourse. Our research addresses the impact of rapid urbanisation on two types of Tamil temple-cities, one with a single, dominant temple at the centre (Madurai) and the other with multiple temple-nodes within the urban fabric (Kumbakonam). In scale, one is a major and rapidly expanding city with a population approaching three million (Madurai) versus a more modest town in an agricultural heartland (Kumbakonam). It should be noted that compared with many cities in Tamil Nadu, both Madurai and Kumbakonam have been addressed by previous scholarship, though uneven and much very old, or addressing very different material or issues.
Popular conceptions of Madurai are as a temple-city dominated by the concentric streets of the old town and the largely sixteenthseventeenth century Minakshi-Sundareshvara temple dedicated to Shiva and his consort at its heart. Not only are there many more Hindu temples within the city's limits, both Shaiva and Vaishnava, but other religious communities' architectural heritage is also evident. Since 1948, the symbol of Madras State (from 1969 Tamil Nadu) has been the characteristic towering temple gateway or gopuram. Despite local legislation to limit the height of surrounding structures, mobile phone masts and highrise hotels now challenge the dominance of Madurai's soaring gopurams on the city's skyline.

Kumbakonam on the banks of the river Kaveri is in the heart of the agriculturally-rich delta region that is often considered the cradle of Tamil culture. Amid a dense network of villages, irrigated rice-fields and temples, Kumbakonam's plan is configured around multiple temples to Shiva and Vishnu, their interconnecting processional streets, densely-built brahmin settlements (agraharams) and large water-filled temple tanks. Among the earliest temples built during Chola rule is the ninthcentury Nageshvara, still in active use. Between the fifteenth and seventeenth centuries, the construction and expansion of several large Vaishnava temples with towering gopurams and the establishment of new connecting processional avenues reconfigured the urban landscape (Carl et al. 1996, Nanda 1999a, 1999b). Of particular ritual significance within the city is the large water-filled Mahamakam tank. During the twelve-yearly Mahamakam festival, last celebrated in 2016, huge numbers of pilgrims swell the town's population during which they bathe in the tank at an auspicious moment.

\section{THE PURPOSE OF DIGITAL PLATFORMS FOR CONSERVATION MANAGEMENT PLANNING IN THE CONTEXT OF TAMIL NADU TEMPLE TOWNS}

At Kumbakonam and at Madurai, a research project seeks to contribute clarity to contested restorations of temple buildings. In the early twentieth century archaeologists were often outraged at the 'renovation' of South Indian temples, largely unaware at the time that these practices have in fact continued over a millennium. Nevertheless, today the conflict in approach between UNESCO and religious communities is at a heightened level. In the context of museums, Flynn has argued that virtual heritage can enable "a kinaesthetic sense of presence in the past" (Flynn 2010). We aimed to build digital models that might begin to enable the more precise location of documentation as well as to create a platform for discourse. This paper explores the potential for using the enhanced visual modalities of digital tools to bridge between methods of codification and immersion for cultural heritage management in a particular context of contested authority. The issues at hand are hugely complex: the historical and intangible cultural significances overlay religions and generations all occupying the same physical space at the same time. Communication is a key concern for those working to improve infrastructural and civic features whilst compelled to respect traditions and both tangible and intangible heritage. The question of how to better map or delineate these complex interactions becomes a key pre-requisite of successful future conservation planning.

McCarthy has argued that "the fundamental and most important reason (for preserving digital cultural heritage resources) is to give future societies the opportunity to make decisions based on the best information available" (McCarthy 2007). The aim of the digital surveys and their collation with historic surveys in this 
project is in line with this view. The foundation of the Archaeological Survey of India (ASI) in 1861 followed from that of the Asiatic Society founded in 1784. That the ambition to visually record built heritage for future generations was anticipated so long ago is, in certain cases, a great asset to augmenting our documentation today. The photographic records of the ASI and others have been used as a means to verify the visual evidence available today. In some instances, historic records also provide measured drawings. For architects, the ability to draw to scale is at the core of their authority typified in western terms by a critical comparison between measured depictions of the orders "ancient and modern" with dimensions to copy (Fréart 1707). The clarity of such instructive methods remains hard to supersede. However, in the Tamil temple contexts, the tradition and the practice of temple building are unbroken, they are not adopted, they have remained in active use. Inevitably, practices are often developed iteratively, then adopted in another context, altering slightly and potentially becoming unrecognisable. Disparate approaches must be acknowledged. Is it feasible for an immersive and navigable digital model to be both instructive in this way and informative at another level?

Digital interfaces offer huge opportunities for interaction engagement and non-destructive observation but may also present risks of alienation and exclusion together with the potential disarmament of expertise and hierarchies of knowledge as Megha Chand Inglis has explored with regard to the transmutation of craft traditions for the Sompura temple architects in northwest India (Chand Inglis 2016). Is there a path to communicate visually in the context of disputed expertise and traditional practice by assuming a collective determination to manage and maintain historic sites? Or do the shared realms that they enable have distinct applications for documentation and visualisation? To what extent might they augment or diffuse the dynasties of decision making for heritage assets, is it really feasible for the recording to be complete and more appropriate for it to evolve? Laser scanners can record the extent and surface form of interior spaces in darkness. The three-dimensional digital models that they enable may, in many circumstances, have limited application beyond that of documentation or visualisation, yet these do help us to see. For architects, the capacity to derive accurate orthogonal depictions of remote and complex geometries is tantalising. The role of measurement in our ability to read things to scale is at the core of our capacity to interpret and to invent. The translation of measured surveys in the exportation of western architectural traditions from archaeological trophies provided the foundation of a designer's authority as the eighteenth century developed. Their esteemed accuracy was deemed to determine a special accolade of authenticity in terms of following a broken tradition for the emergent architectural profession. At Kumbakonam and at Madurai, using a combination of Structure-From-Motion and terrestrial laser scanning we aimed to build digital interfaces that might begin to enable sectional readings of these great masonry gopura. A huge quantity of data is collected relatively instantly but at what point is it turned to critical effect? At the same time the iconographic and constructional logic is re-read, re-drawn and re-interpreted. Yet the difference here is that the tradition and the practice that relates to that tradition are unbroken, they are not adopted, foreign nor ruined artefacts, they remain in active use. How then, is this geometric data best clarified, codified, shared or deployed?

Model making in the form of physical and digital models, drawings and re-drawings have always fed the quest for visual evidence enabling new readings and the potential for multiple means of calibration of historic environmental conditions against documentary evidence. The capacity of the laser scanner or even simple photogrammetry to deliver measurable three-dimensional point clouds with the enriched benefit of photo-realistic colouring provides significant and obviously fast-moving opportunities to re-occupy, to non-destructively observe and envision change in our material world. In a post-colonial era of massive population growth in which climate change, the contestation of cultural heritage management practices and the technological potential for leapfrogs in development may risk or demand the drastic alteration of our built environment, these modelling tools appear invaluable.

\subsection{Limitations}

It should be noted that there were restrictions to the quantity and quality of data that it was possible to collect. Whilst permissions were sought in advance, fast moving governance arrangements meant that these were not secured in time for much of the surveys which were therefore partial. The three surveys are thus incomplete to date yet each offers a clear pathway for offering potential service in terms of discussion of specific concerns. In part three, each of these are set out to suggest their potential viability as consultation tools. The project will also include a degree of mapping potentially building on the methods of Kasiannan et al but this has yet to commence (Kasiannan and st International, 2007).

\section{TWO CASE STUDIES}

\subsection{The Pudu Mandapam at Madurai}

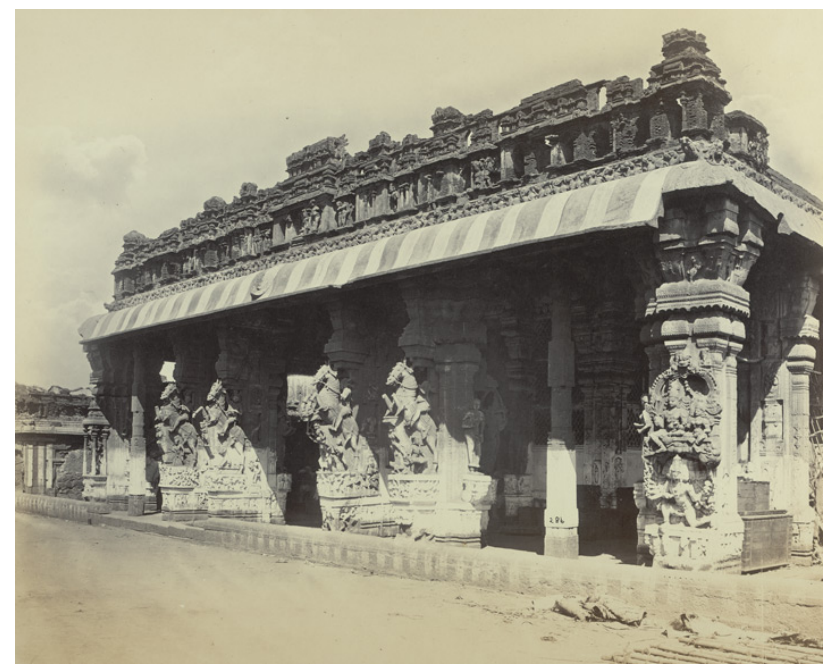

Figure 3. (Western Side of the Pudu Mandapam) The Minakshi Sundareshvara temple. 1868, Edmund David Lyon. (C) British Library Board Shelfmark: Photo 212/1(37)

The Pudu Mandapam ('New Hall') built in the 1630s during the reign of Tirumala Nayaka (1623-59) extends from the East gopuram of the main temple. What distinguishes this massive columned hall, measuring around 100 by 25 metres, is the volume of impressive figural sculpture. For 34 of the 124 huge columns have a two-metre or more high three-dimensional figures of mounted cavalrymen, mythical yalis and Hindu deities sculpted from the monolithic column shaft and sixteen of these columns have figural sculptures on both sides. It now contains numerous tailors' shops in its side aisles although the nave remains secured for twice-yearly ritual events. The Pudu Mandapam received an extraordinary degree of focus in terms of its documentation from the 1780 s and through the nineteenth century when photographic 
surveys in 1858,1868 and the 1890 s provide us with a significant body of accessible visual reference. These photographs were subsequently used both as a measure of comparative condition survey but also as a means of navigation. Using a CFARO focus $\mathrm{X} 130$ 3D just two laser scans at the East end and some structure from motion photogrammetry at the West front, we sought to capture a skeleton of the whole with the means to delineate some details.

\subsection{The Nageshvara Temple at Kumbakonam}

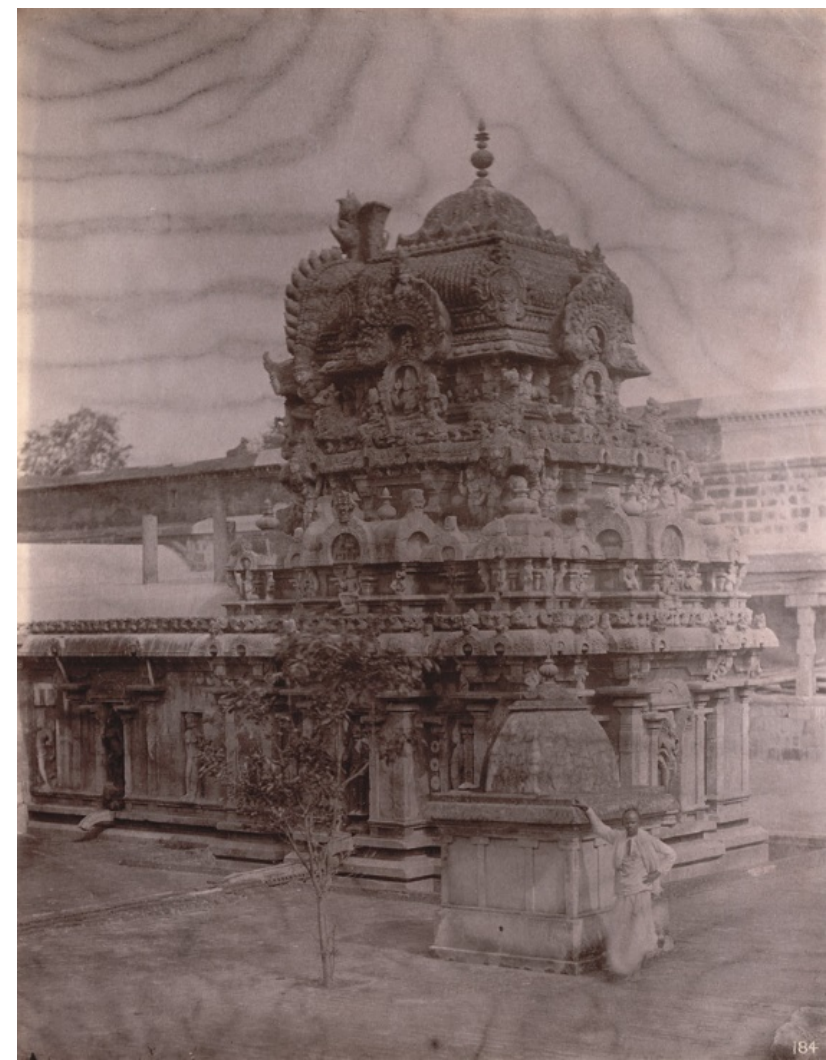

Figure 4. View from the north-west corner of the shrine of the Nageshvara Temple, Kumbakonam, 1892, Alexander Rea (C) British Library Board Shelfmark: Photo 1003(2410)

Kumbakonam was of importance during the Chola dynasty (c. $9^{\text {th }}$ $13^{\text {th }}$ centuries) and today contains eight temples dedicated to Shiva and twelve to Vishnu. The Nageshvara (Shiva) temple is one of the earliest surviving stone temples in the city that has not been subsequently replaced by a more recent structure. Dedicated in the $880 \mathrm{~s}$, it is one of the finest examples of early Chola-period art and architecture in Tamil Nadu. Today the upper stories of the gopura and shrines are painted brightly, and various additions and renovations have caused concern with conservation authorities and the public. Restoration work in 2015 ahead of the Mahamakam festival resulted in many of the most highlyregarded sculptures, including narrative reliefs of the scenes from the Ramayana, being damaged by high-pressure water-blasting intended to clear the structures of surface sediments and deposits. A series of photographs from the Architectural Survey of India taken in 1892 provide some perspective as to the condition of the buildings and sculptures at that time. Here, along with a set of $360^{\circ}$ images taken with a Theta IV, and a terrestrial laser scan survey of the temple prakara or courtyards using 24 scan locations producing a pointcloud of $3.5 \mathrm{bn}$ points with a mean point error of $5.7 \mathrm{~mm}$.

\section{DEPLOYING DIGITAL MODELS FOR PARTICULAR TASKS}

\subsection{Reviewing change in the Historic Urban Landscape; Modelling Urban Encroachment}

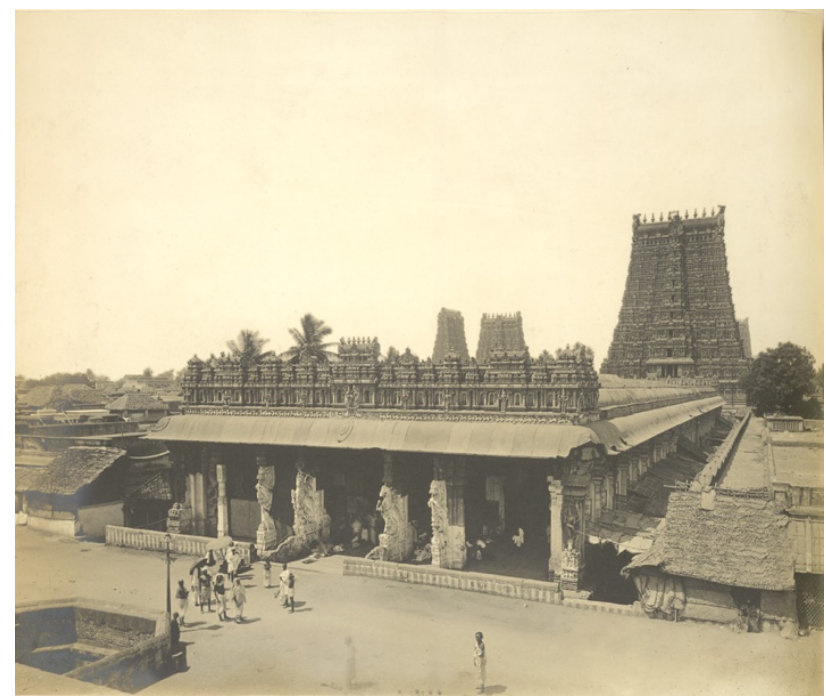

Figure 5. General view of Pudumandapam from the north-east, near Minakshi Amman Temple, Madura. ASI 1899-1900 (C) British Library Board Shelfmark: Photo 1008/4(355)

The great east gopura that once dominated the urban landscape at Madurai as shown foregrounded by the Pudu Mandapam in the photograph of 1899-1900 (Figure 5), are becoming embedded within a much denser visual field in the context of mass rapid urbanisation. These developments and impacts are not by any single agency, they are an accumulation of multiple minor adjustments. While the immediate surroundings of the temple have from 2005 been sanitised and paved, railings have been erected, trees planted and watchtowers placed at each corner and entrance, the visual field remains hugely distracting. Looking at the orthogonal projections of the point cloud it is clear that the height of the gopura are still the most dominant features, yet in perspective and from the ground, this perception is compromised. A plan view of the street scene and overhead wires demonstrates the proximity of objects to the monument.

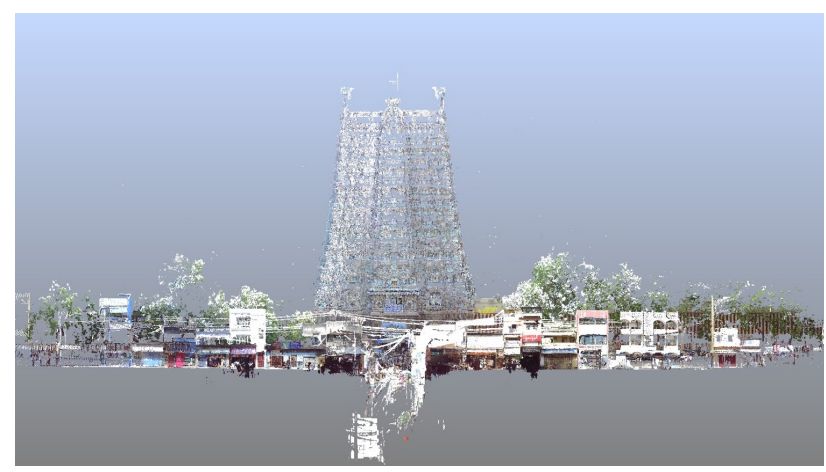

Figure 6. Orthophoto of TLS showing front elevation of Western gate of Minakshi temple, Madurai, India 


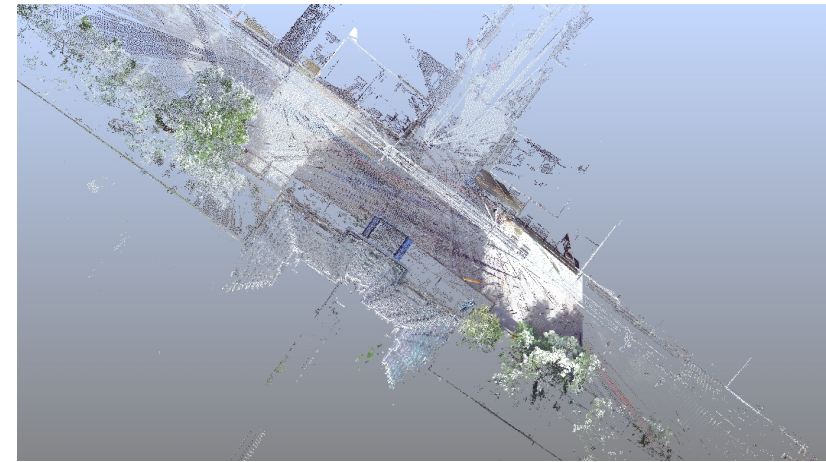

Figure 7. Plan view of TLS of Western gate of Minakshi temple, Madurai, India

A suggestion from this study is that through manipulation of the digital model and editing of elements it might be feasible to make persuasive cases for the decluttering of the scene. As these items are not restricted to commercial and private enterprises but include town landscaping, municipal signage and lighting as well as temple security features, the 'playing field' of the model could provide an environment in which these potentially less sensitive items could be negotiated.

\subsection{Identifying change over time}
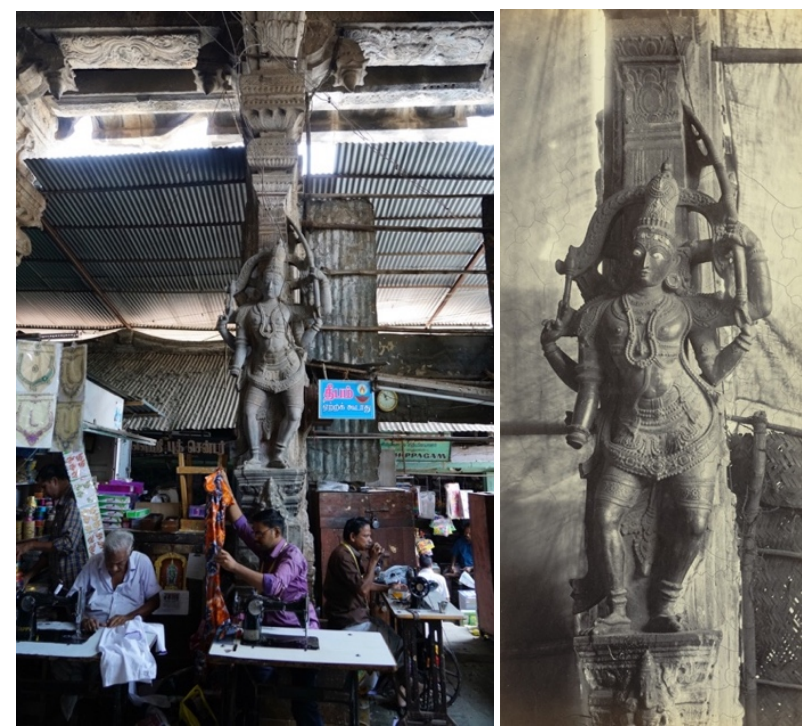

Figure 8. Left: Photograph of interior of Pudu Mandapam August 2018, (OP) and Right: Figure in Trimul Naik's Portico [Pudu Mandapa]. c. 1868, Edmund David Lyon

(C) British Library Board Shelfmark: Photo 212/1(23)

On $2^{\text {nd }}$ February 2018, a devastating fire broke out amongst the shops within the Minakshi Sundareshvara temple (Sundar 2018). The fire caused the destruction of over 36 shops in the stone built 400-year old Veera Vasantharayar Mandapam and was attributed to an electrical fault (Govindarajan 2018). The granite pillared hall has subsequently been almost entirely dismantled. As a consequence, the nearby Pudu Mandapam was temporarily closed as a precautionary measure. The event certainly indicates that the operation and management of the historic building should be reviewed and preventative measures considered in order to secure its on-going use as an active and occupied environment. However, there are complex layers of governance and stewardship that intersect governmental, religious and community authority which make the design and delivery of such interventions challenging. There are records dating back to the late nineteenth century of tailors occupying the Pudu Mandapam. Since 2010, efforts have been made to relocate them to a new building nearby, but the project has stalled. Their occupation of the space is intense but nevertheless ordered by the extraordinary built environment surrounding them.

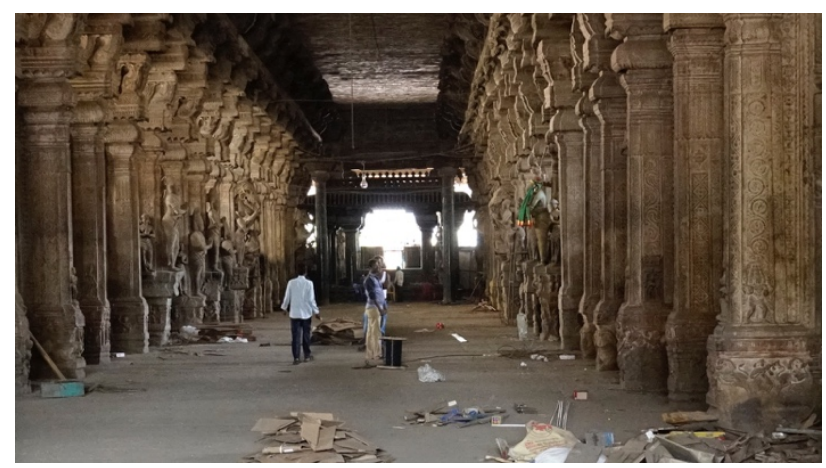

Figure 9. Photograph of interior of Pudu Mandapam, August 2018 (OP)

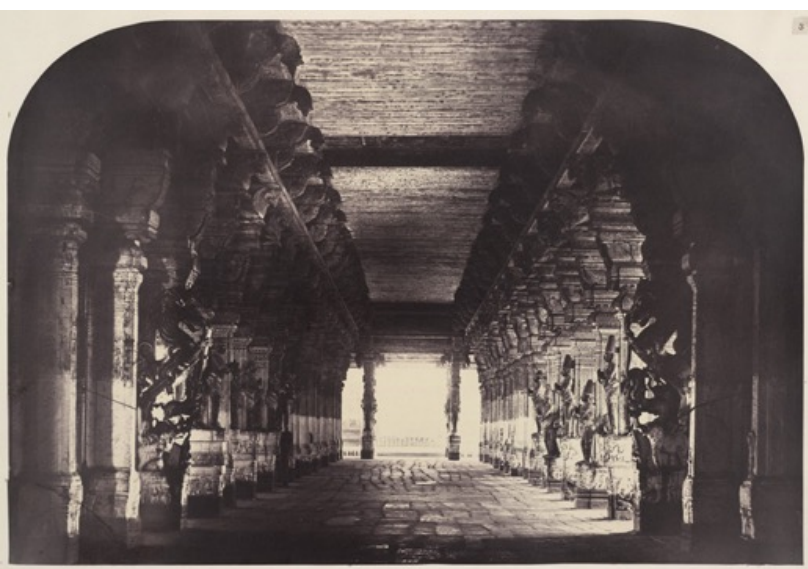

Figure 10. View of the nave from the Simhasanum at the west end. Date: 1858, Linnaeus Tripe (C) British Library Board Shelfmark: Photo 953/2(3)

Detailed examination of images in comparison to 150-year old photographs reveals that the sculptures are largely intact, albeit surrounded by furniture and activity. The presence of this rich source of historic photographic documentation in general removes the sense of urgency to tidy up, restore or alter the ongoing use of the building. It lends confidence where an instinctive reaction might be alarm at the intensive occupation of such a space. The critical observable change to the interior of the "nave" (Figures 9 and 10) is only the apparent loss of the stone paving visible in photographs from 1858 (Figure 10), 1868 and 1882. The space is physically inaccessible to the public and only used for ceremonial purposes, the photograph is taken from between railings. It is not clear whether a cement screed has been simply been applied over the surface or if a wholesale replacement has taken place.

Remarkably, three different sets of scale drawings were made of this single building and its sculptures in the 1780s, 1801-5 and 1826-31, now held in three collections: the Victoria and Albert Museum, the British Library and the Royal Asiatic Society, all in 
London (see Figure 11; Branfoot 2001). The 1780s drawings were accompanied by bronze scale models of 18 of the columns. These enable further historical correlations to be made, here confirming the state of alterations over a 230 -year period to be minimal. Were it possible to achieve a complete digital survey today, it would be valuable to compare these.
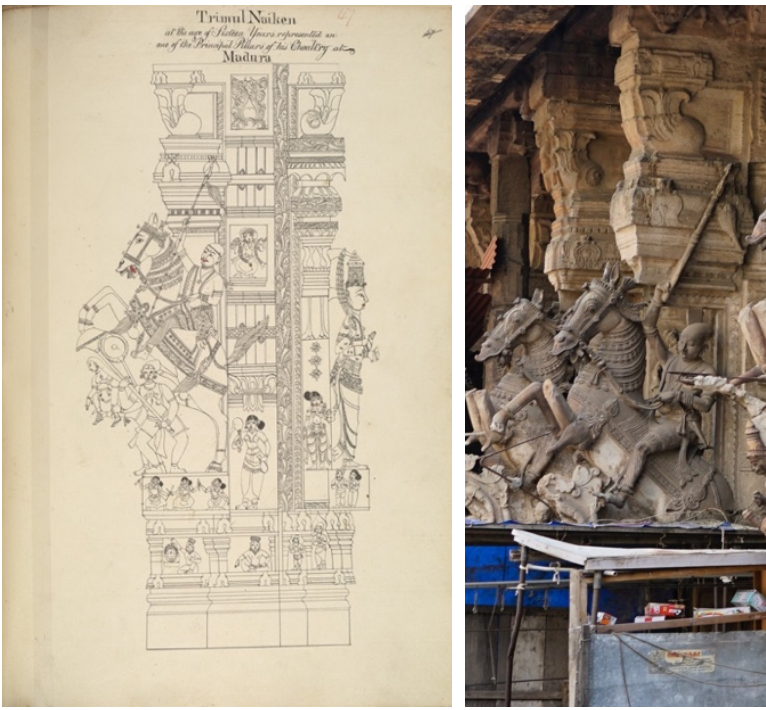

Figure 11. Left: Pen and ink drawing of a column with an equestrian figure at the entrance of the Pudu Mandapam Anonymous; Pen and ink on paper; Date: c.1801 - 1805; (C) British Library Board Shelfmark: WD1063, Right: Photograph of West front 2018 (OP)

Today the building is protected by railings but these in turn are used as a means to fix signs, to support further small structures and all space around the building is filled up. Again, the potential for a digital model to provide the means to negotiate the qualities of revised judgements or adjustments to decisions with respect to the placement of municipal infrastructure such as street lighting, signage, electrical distribution and refuse collection could be persuasive.

It is however, the vulnerability of the magnificent yalis (mythical creatures that are part horse, elephant, griffin and lion) and equestrian figures on the east and west facades that stirs most anxiety. Here it is clear, for example that two equine forelimbs have broken away since the original photograph was taken. Whilst damage may be inevitable or accidental, clearly the more documentation that is available, the more informed any repair may be.

In order to examine certain elements more closely, a minor photogrammetric survey using CIPA $3 \times 3$ rules (Waldhäusl, P Et al 2013) was used to create a fragmentary mesh made with Agisoft Photoscan. This reveals that a certain degree of reconstruction has taken place to the supporting figures when compared to old photographs - possibly using stiff lime putty. Although rotating the 3D mesh model over an image is not feasible in photoscan and therefore a side by side visual match is required, it is possible to import the files as OBJ or PLY into $\mathrm{CAD}$ programmes such as Vectorworks which do allow the placement of an image on an underlying layer.

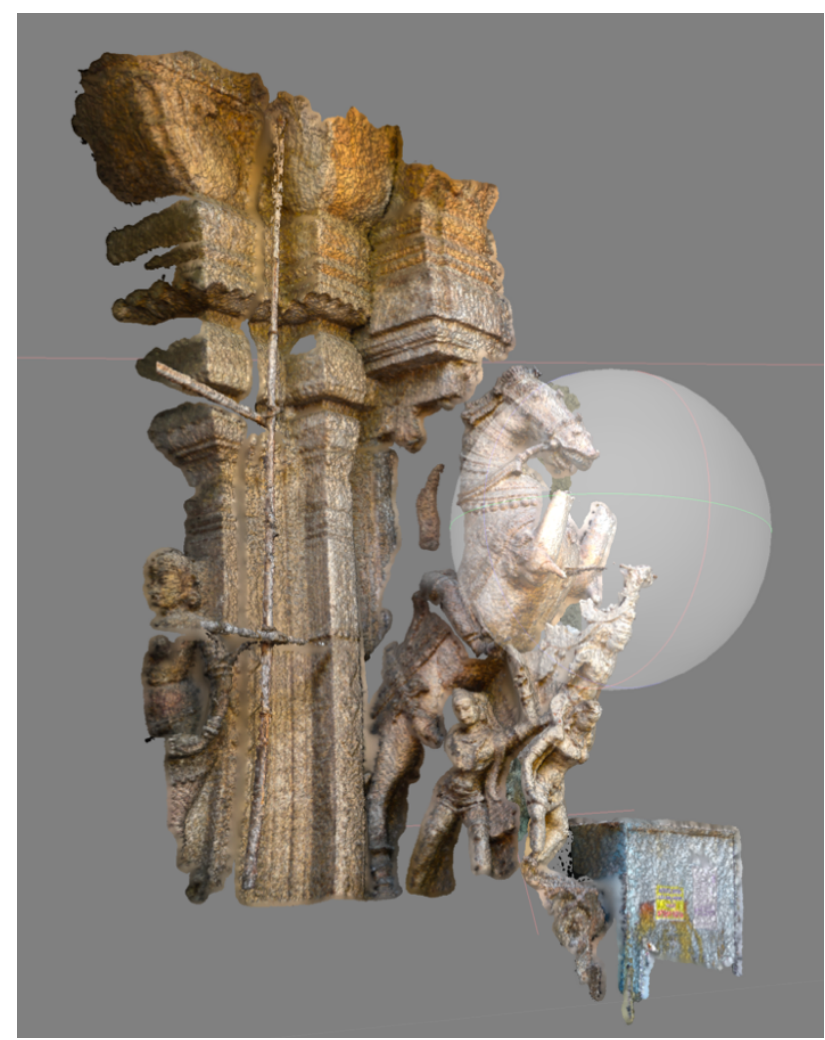

Figure 12. SFM Mesh of Yali on front façade of Pudu Mandapam from photographs taken 2018

\subsection{Suggesting alteration}

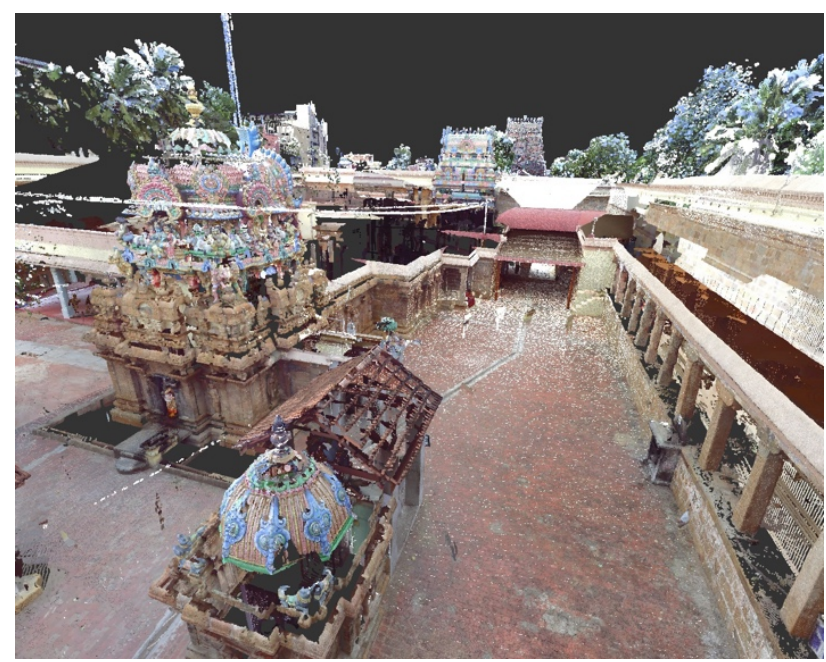

Figure 13. TLS of shrine at Nageshvara temple, Kumbakonam

The significance of the statuary at the Nageshvara temple in Kumbakonam has been noted briefly above. Its current presentation is shown here through a set of scans navigated and adjusted in what is theoretically a simple, shareable and accessible format in Autodesk ReCap Pro.

Removal or 'restoration' in conservation practice is always a contentious approach, particularly when, as in this case, the removal relates to historical "universal values" reigning over the will of current ritual practice and religious belief. That said, on occasion it is a valid argument to consider whether such additions 
should be debateable and whether later accretions are a benefit or a detraction from heritage assets. Here a simple sequence of digital extraction enables the consideration of a change to the existing arrangements. Additional structures to shelter popular shrines have been built up against the walls of the oldest parts of the temple (compare with Figure 4). Challenging their existence is a difficult case to make, given that they reflect the ongoing popularity and in many cases are seen to demonstrate devotion as gifts to the temple. Nevertheless, they crowd the space and obscure the visual appreciation of the original building. In simply digitally extracting these items, it is possible to demonstrate a 'rectified' view, even if it never happens for other reasons. See figure 13 and the sequence in figure 14.

\section{DISCUSSION}

A core issue at the heart of this project is, how can architectural conservation accommodate to the needs of religious practice? At a finer level the research asks what do various agamas say about renovation? How is 'renovation' understood by various contemporary actors? Who is responsible for leading the renovation projects (e.g. individuals or groups) and where has the money come from? Are trained stapathis involved with Agamic knowledge? There is an ambition for this knowledge to be made more accessible but to what extent can it readily be managed through visual documentation practices.

The creation of three-dimensional models in order to consider design proposals, alterations, developments is a standard architectural tool. However, for conservation planning, it is less commonly used. In the context of an environment in which there are multiple stakeholders with multiple interests and various determinations of authority and power, the ability to nondestructively but visually accurately propose alterations, changes and adjustments is surely valuable. Although there are 38000 temples in Tamil Nadu, each will raise different concerns and have different contextual circumstances which is where the potential to create rapid and cheap digital documentation of such buildings would be inherently desirable. The testimony of the historic photographs from the nineteenth century demonstrate the huge value of visual recording for future generations.

Clearly the opportunity to complete the surveys in detail, to extend the remit to other buildings is highly desirable. The enormity of the potential documentation task facing HR\&CE requires innovative enablement of potentially crowd-sourced data acquisition techniques - yet these are certainly within reach. To work with the historic images and consider potential for feature mapping in more depth is desirable building on recent work (Maiwald et al., 2018). Work to enhance the interoperability of $3 \mathrm{D}$ model navigation is required to draw the debate to a wider audience and to make it more inclusive. By modelling changes over time at these sites, it would be possible to create a more nuanced reading of their development and the lively path of transformation. The examples here are all related to simple visual observations of built heritage, they are not related to the significant intangible aspects of these buildings' value and role. The deeper discourse relating to this project which focuses on translating various relevant texts is perhaps inevitably a path that remains in parallel, yet it is not inconceivable that various digital 'layers' could be used to highlight relevant considerations arising from these.
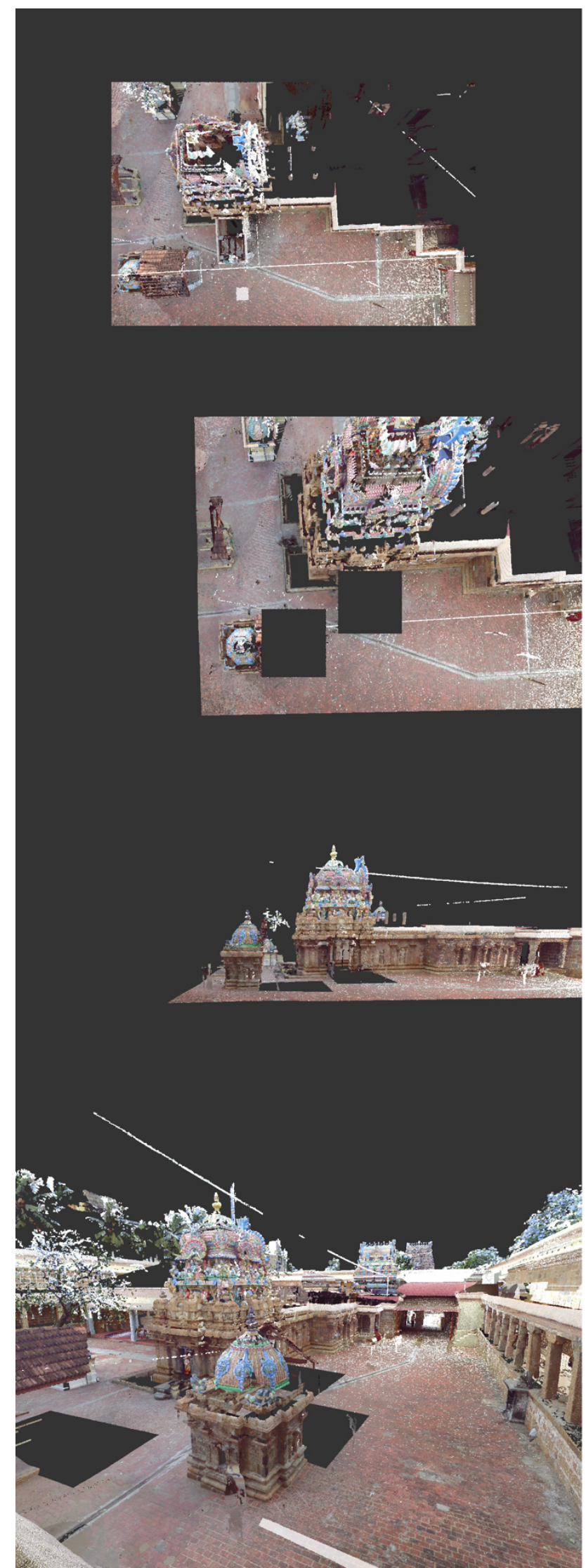

Figure 14. Sequence showing digital removals 


\section{CONCLUSION}

Seeking to resolve differences, Boito proposed the textual analysis methods of classical philologists as the best approach to building conservation, implicating phil - love - as a critical constituent (Boito 1893). However, in instances of multiple sources of authority and affection - religious, cultural and professional - questions remain as to whose love and by which methods that patrimony is administered. Smith raised the issue of Authorised Heritage Discourse as a challenge to the professed judgements of experts (Smith 2006). The use of 3D digital techniques to record living religious heritage on Asia is growing (Rahig, M et al., 2017). The need for methods that enable discourse between those primarily concerned with the conservation of intangible as opposed to tangible heritage is acute in the context of Tamil Nadu temple towns. The historic urban landscapes as well as the continuous religious practices are exceptional and unique. Albeit not as complete as a LIDaR survey might have been, the ability to use terrestrial laser scanning to encapsulate the critical contrast in scale of these sites in the city context is a significant step forward. The capacity to work the $3 \mathrm{D}$ models in contrast to the old photographs, where they are available, has enabled reconsideration of assumptions of dereliction or decay. In the context of contested approaches to conservation, accessible digital models ideally present an open space for discourse. Non-linear development and disparate approaches must be acknowledged. Greater efforts to enhance communication and shared practice between researchers, policymakers, public and practitioners should be facilitated. In order to better "use and enhance" heritage we must participate in outward looking discourse that genuinely connects with the diversity of society.

\section{ACKNOWLEDGEMENTS}

This research was funded by the AHRC/ICHR project, Tamil Temple Towns: Conservation and Contestation (2018-2020).

\section{REFERENCES}

Boito, C., 1893. Questione Practiche Di Belli Atri. Art Journal, 1839-1912, 280.

Branfoot, C., 2001. Tirumala Nayaka's "New Hall" and the European Study of the South Indian Temple. Journal of the Royal Asiatic Society 11.2, 191-218.

Branfoot, C., 2013. Remaking the past: Tamil sacred landscape and temple renovations. Bulletin of the School of Oriental and African Studies 76, 21-47.

Byrne, D., 1991. Western hegemony in archaeological heritage management. History and Anthropology 5, 269-276.

Carl, P., Dallapiccola, A., Michell, G., Nanda, V., 1996. Cambridge Kumbakonam Project: Kumbakonam: a ritual topography. Architectural Design 66, 30-33.

Chand Inglis, M., 2016. Reimagining tradition: the Sompura hereditary temple architects of Gujarat. PhD Thesis, Cardiff University.

Flynn, B., 2010. The Morphology of Space in Virtual Heritage, in: Cameron, F., Kenderdine, S. (Eds.), Theorizing digital cultural heritage: a critical discourse. MIT Press: Cambridge, Mass. ; London, 349-368.
Fréart, R., 1707. A parallel of the antient architecture with the modern 2nd ed / with large additions. ed. London : D. Brown, 1707., London.

Govindarajan, V., 2018. 'Fire in Madurai's Minakshi temple sparks demand for shops to be evicted from complex' https://scroll.in/article/867574/fire-in-madurais-Minakshitemple-sparks-demand-for-shops-to-be-evicted-from-complex (accessed 28/2/19)

Kasiannan, S., st International, C.S., 2007. Mapping traditional belief systems and establishing contemporary connections in a historical landscape. Int. Arch. Photogramm., Remote Sens. Spat. Inf. Sci. - ISPRS Archives 36.

Maiwald, F., Schneider, D., Henze, F., Munster, S., Niebling, F., Photogrammetry, I.T.I.M.-t.S.T., 2018. Feature matching of historical images based on geometry of quadrilaterals. Int. Arch. Photogramm., Remote Sens. Spat. Inf. Sci. - ISPRS Archives 42, 643-650.

McCarthy, G., 2007. Finding a future for digital cultural heritage resources using contextual information frameworks. in: Cameron, F., Kenderdine, S. (Eds.), Theorizing digital cultural heritage: a critical discourse. MIT Press: Cambridge, Mass. ; London, pp.245-60

Nanda, V., 1999a 'Temple City of Kumbakonam'. In: Michell, G. (ed), Eternal Kaveri: Historical Sites Along South India's Greatest River. Marg Publications: Mumbai, 107-22.

Nanda, V., 1999b. Kumbakonam: The Ritual Topography of a Sacred and Royal City of South India. Archaeology International $3,43-48$.

Rahig, M., Luib, A., 2017. Sri Dalada Maligawa - 3D-Scanning and Documentation of the Temple of the Sacred Tooth Relic at Kandy, Sri Lanka. ISPRS Ann. Photogramm. Remote Sens. Spatial Inf. Sci., IV-2/W2, 2017. doi.org/10.5194/isprs-annalsIV-2-W2-229-2017

Silverman, H., 2011. Contested Cultural Heritage. SpringerVerlag: New York.

Smith, L., 2006. The Uses of Heritage. Routledge: London.

Sundar, S., 2018. 'Fire in Madurai Minakshi Temple', The Hindu, Madurai https://www.thehindu.com/news/ cities/Madurai/fire-in-madurai-Minakshi-temple-over-30-shopsgutted/article22638277.ece (28 Feb 2019)

UNESCO, Convention concerning the Protection of the World Cultural and Natural Heritage : adopted by the General Conference at its seventeenth session, Paris, 16 November 1972.

Waldhäusl, P., Ogleby, C. L., Lerma, J. L. \& Georgopoulos, A. 2013. 3 x 3 rules for simple photogrammetric documentation of architecture.URL:http://cipa.icomos.org/wpcontent/uploads/201 7/02/CIPA_3x3_rules_20131018.pdf (28 Feb 2019)

Worthing, D., Bond, S., 2008. Managing built heritage : the role of cultural significance. Oxford: Blackwell. 